\title{
PENGARUH KEMAMPUAN INTELIGENSI DAN TASK COMMITMENT TERHADAP PRESTASI BELAJAR MATEMATIKA
}

\author{
Febryanti*
}

\section{ABSTRACT}

This study is based on the number of children who actually have the potential to achieve high learning, but it has low achievement, because some factors that do not have, such as task commitment. This study aims to determine how the influence of intelligence and task commitment to the achievement of learning mathematics students SMPN 4 Sendana. This research type is correlation research. The population in this study is the students of class VIII SMP Negeri 4 alone. Sampling technique used "Purposive Sampling". Data collection techniques used questionnaires and documentation. While the data analysis technique is a quantitative analysis, which uses multiple regression techniques. The results of this study indicate that the ability of intelligence to positively affect the mathematics learning achievement of students class VIII SMPN 4 Sendana, with regression coefficient - 0.110 with a significant level of 0.516 and $t$ arithmetic of -0.657. task commitment has a positive effect on student learning achievement, with regression coefficient equal to - 0,053 with significant level 0,422 and t count equal to -0,812. together intelligence ability and task commitment have an effect on student's mathematics learning achievement, with $F$ count 0,460 at significant level $5 \%(0,05)$ value $p=0,635$.

Keywords: Intelligence Ability, Task Commitment

\section{PENDAHULUAN}

Bagian yang terpenting dalam kehidupan suatu bangsa adalah pendidikan, yang pada dasarnya sudah ada pada saat manusia mulai menghadapi berbagai masalah kehidupan. Kemudian dalam perkembangannya pendidikan menjadi suatu lembaga yang semakin banyak jumlah manusianya.

*) Program Studi Pendidikan Matematika, Universitas Al Asyariah Mandar E-mail:febryanti.lawa@gmail.com 
Berbicara masalah pendidikan maka tidak terlepas dari suatu lembaga yang menjadi inti dari pendidikan itu sendiri, yaitu lembaga sekolah dimana anak-anak di didik untuk menggali segala kemampuannya. Keberhasilan seorang anak dalam pendidikan ini sering ditunjukkan dengan nilai-nilai sebagai hasil belajar yang sering disebut juga prestasi belajar. Penilaian ini sudah menjadi sistem yang terintegrasikan dalam sistem persekolahan kita. Meskipun memberikan nilai angka tidak meningkatkan proses belajar bahkan sering menghambatnya (apalagi kalau salah angkanya). Karena sering kali guru hanya melihat nilai yang diperoleh peserta didik dari tugas-tugas dan nilai ujian saja, guru sering melupakan tugasnya yang selain mengajar juga merupakan observer terhadap anak didiknya hingga seorang guru seharusnya mengerti akan latar belakang peserta didiknya. Banyak hal yang mempengaruhi prestasi belajar seorang anak, seperti inteligensi, kreatifitas ketekunan dalam belajar dan lain-lain. Seharusnya guru mengidentifikasi faktor-faktor yang Mempengaruhi prestasi belajar anak, agar dapat diperkirakan faktor apa saja yang menghambat mereka memperoleh prestasi belajar yang baik.

Penyelenggaraan sistem pendidikan disekolah-sekolah umumnya bersifat klassikal-massal, artinya memberikan perlakuan yang standar (rata-rata) kepada semua peserta didik, padahal setiap peserta didik mempunyai kebutuhan yang berbeda-beda. Seringkali sekolah kadang malah menjadi penjara bagi pengembangan kemampuan intelektual seorang anak. Karena berbagai peraturan yang ada justru mengungkung imajinasinya, hingga mereka merasa tidak bebas berekspresi. Maka 
benarlah yang dikatakan seorang ilmuwan terkenal Albert Einstein "satusatunya yang menghambat saya adalah pembelajaran saya" (Scott Thorpe, 2002:57). Dengan kungkungan seperti ini anak-anak yang sebenarnya memiliki potensi tidak dapat berprestasi maksimal dan seringkali mengalami kegagalan. Kegagalan-kegagalan yang menimpa seorang anak akan memberi dampak yang negatif bagi pembentukan konsep dirinya. Suksesnya prestasi seorang anak dalam sekolah, sukses dalam lingkungan bermain, atau sukses dalam situasi-situasi lain, akan membantu pembentukan konsep diri. Sehingga konsep yang terbentuk itu akan sangat mempengaruhi bagaimana prestasinya dalam tingkat-tingkat perkembangan selanjutnya, demikian seterusnya.

Dari hasil observasi, ternyata banyak anak-anak yang mempunyai IQ tinggi mempunyai prestasi belajar yang dibawah anak-anak yang memiliki IQ rata-rata. Keberhasilan belajar seseorang sangat ditentukan antara lain oleh kemampuan kognitif, tetapi ternyata bahwa faktor non kognitif tidak kalah penting bahkan mempengaruhi perkembangan seseorang. Banyak anak-anak yang sebenarnya berpotensi untuk berprestasi bagus, namun justru memiliki prestasi rendah, karena beberapa faktor yang mendukung untuk berprestasi yang tidak dimilikinya, seperti task commitment. Namun hal terpenting yang akan dibahas dalam penelitian ini bukan mengapa bakat anak tidak teraktualisasikan, namun hal terpenting yang akan dibahas adalah mengapa anak-anak yang mempunyai intelegensi tinggi sering prestasinya dibawah anak normal, sedangkan anak yang tes IQnya biasa saja prestasi belajarnya lebih baik. Untuk itulah penulis ingin meneliti sejauh mana 
perbedaan pengaruh kemampuan inteligensi dan task commitment terhadap prestasi belajar anak terutama dalam pelajaran matematika yang sangat membutuhkan kemampuan berfikir. Sehingga diharapkan akan mencapai satu kesimpulan faktor intelegensi lebih berperan dalam menentukan prestasi belajar matematika peserta didik atau sebaliknya task commitment lebih berperan dalam menentukan prestasi belajar matematika peserta didik.

\section{METODE PENELITIAN}

Jenis penelitian ini adalah penelitian korelasi. Penelitian ini dilaksanakan di SMPN 4 Sendana dan populasi dalam penelitian ini siswa kelas VIII dengan jumlah sampel sebanyak 40 siswa. Instrumen yang digunakan dalam penelitian ini adalah instrumen baku,dimana peneliti mengumpulkan data inteligensi dan task commitment dengan menggunakan koensioner dan data nilai hasil prestasi belajar matematika diperoleh dari hasil nilai rapor semester 1 dan 2 .

\section{Tehnik Analisis Data}

\section{Analisis Deskriptif}

Tehnik analisis deskriptif dala penelitian ini bertujuan untuk melihat mean, median, modus dan standar deviasinya.

Tabel 1. Rumus Pengkategorian Variabel

\begin{tabular}{|c|c|c|}
\hline No & Rumus & Kategori \\
\hline 1 & $\mathrm{X}<($ Mean - 1 SD $)$ & Rendah \\
\hline 2 & $($ Mean - 1 SD $) \leq \mathrm{X}<($ Mean + 1 SD $)$ & Sedang \\
\hline
\end{tabular}




\begin{tabular}{|l|l|l|}
3 & $($ Mean +1 SD $) \leq \mathrm{X}$ & Tinggi \\
\hline
\end{tabular}

2. Uji Asumsi Klasik

a. Normalitas

Rumus untuk mencari normalitas :

$$
x_{0}^{2}=\sum \frac{(f o-f h)^{2}}{f h}
$$

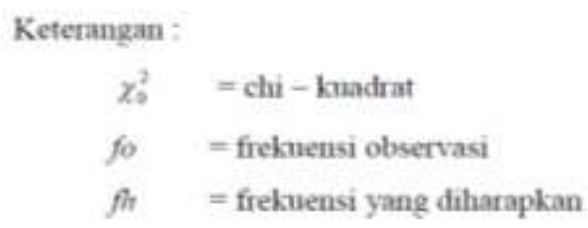

b. Uji Multikolineritas

Rumus untuk mencari uji multikolineritas :

$$
\mathrm{VIF}=\frac{1}{\left(1-\mathrm{R}_{1}{ }^{2}\right)}
$$

Keterangan: Vif $=$ variance inflation factor

$$
\mathbf{R}=\text { nilai koefisien korelasi }
$$

3. Analisis Regresi Linier Berganda

Rumus persamaan umum regresi linier berganda adalah:

$$
\mathrm{Y}=\mathbf{a}+\mathrm{b}_{1} \mathrm{X}_{1}+\mathrm{b}_{2} \mathrm{X}_{2}+\ldots+\mathrm{b}_{\mathrm{n}} \mathrm{X}_{\mathrm{n}}
$$

4. Uji Hipotesis

a. Uji t (T-test)

Rumus untuk mencari uji t:

$$
t=\frac{r \sqrt{n-2}}{\sqrt{1-r^{2}}}
$$


Keterangan: $\mathrm{t}$ : nilai t-hitung

$$
\text { r : nilai koefisien korelasi }
$$

n : jumlah

b. Uji F (F -test)

Rumus untuk mencari uji F :

$$
F=\frac{(R)^{2} / k}{\left(1-R^{2}\right) /(n-k-1)}
$$

Keterangan $: \mathrm{R}=$ koefisien regresi

$$
\begin{aligned}
& \mathbf{n}=\text { jumlah sampel } \\
& \mathrm{k}=\text { jumlah variable independen }
\end{aligned}
$$

\section{Hasil dan Pembahasan}

\section{Deskripsi Hasil Penelitian}

Responden dalam penelitian ini berjumlah 40 peserta didik SMP Negeri 4 Sendana. Data yang diperoleh dari lapangan diwujudkan dalam deskripsi data masing-masing variabel, baik variabel bebas $\left(\mathrm{X}_{1}=\right.$ kemampuan inteligensi dan $\mathrm{X}_{2}=$ Task commitment) maupun variabel terikat $\left(\mathrm{Y}_{1}=\right.$ Prestasi Belajar Matematika). Analisis data meliputi sum,

\begin{tabular}{|c|c|c|c|}
\hline $\begin{array}{ll}\text { Ukuran } & \text { Variabel } \\
\end{array}$ & $\begin{array}{l}\text { Kemampua } \\
\mathrm{n} \text { inteligensi }\end{array}$ & $\begin{array}{c}\text { Task } \\
\text { commitment }\end{array}$ & Prestasi \\
\hline Mean & 97,70 & 85,88 & 84,08 \\
\hline Median & 97,00 & 85,50 & 83,00 \\
\hline Mode & 94,00 & 70,00 & 82,00 \\
\hline
\end{tabular}
mean, median, mode, standart deviation, range, skor min dan skor makx. Disajikan juga daftar tabel 2. distribusi frekuensi berikut.

Tabel 2. Hasil Analisis Statistik Deskriptif Setiap Variabel 
Vol. 13, No. 2, Nopember 2017

Jurnal Pendidikan PEPATUDZU

Media Pendidikan dan Sosial Kemasyarakatan

\begin{tabular}{|c|c|c|c|}
\hline Std. Deviation & 4,79 & 12,26 & 4,86 \\
\hline Variance & 22,98 & 150,37 & 23,61 \\
\hline Range & 16,00 & 54,00 & 19,00 \\
\hline Minimum & 90,00 & 63,00 & 75,00 \\
\hline Maximum & 106,00 & 117,00 & 94,00 \\
\hline $\begin{array}{c}\text { Sum (Jumlah Skor } \\
\text { Perolehan) }\end{array}$ & 3908,00 & 3435,00 & 3363,00 \\
\hline
\end{tabular}

\section{Kemampuan Inteligensi}

Data kemampuan inteligensi diperoleh dari instrumen berupa angket yang terdiri dari dua jenis pernyataan, yaitu pernyataan positif dan negatif. Penilaian menggunakan skala likert dengan 5 alternatif jawaban Untuk penyekoran pernyataan positif yaitu sangat setujuh adalah 5 , setujuh adalah 4 , netral adalah 3 , tidak setujuh adalah 2 , dan sangat tidak setujuh adalah 1 .

Berikut ini adalah penyajian distribusi frekuensi data tingkat inteligensi peserta didik

Tabel 3. Distribusi Frekuensi Tingkat Intelegensi Peserta Didik

\begin{tabular}{|c|c|c|c|c|c|}
\hline \multirow{2}{*}{ No. } & \multirow{2}{*}{$\begin{array}{c}\text { Interval } \\
\text { Kelas }\end{array}$} & \multicolumn{5}{|c|}{ Frekuensi } \\
\cline { 3 - 6 } & Absolut & Kumulatif & Relatif & Kumulatif \\
\hline 1. & $87-89$ & 0 & 0 & 0 & 0 \\
\hline 2. & $90-92$ & 6 & 6 & 15 & 15 \\
\hline 3. & $93-95$ & 10 & 16 & 25 & 40 \\
\hline 4. & $96-98$ & 8 & 24 & 20 & 60 \\
\hline 5. & $99-101$ & 6 & 30 & 15 & 75 \\
\hline 6. & $102-104$ & 5 & 35 & 12,5 & 87,5 \\
\hline 7. & $105-107$ & 5 & 40 & 12,5 & 100,00 \\
\hline
\end{tabular}




\begin{tabular}{|l|c|l|l|l|}
\hline Total & 40 & & $100 \%$ & \\
\hline
\end{tabular}

Berdasarkan Tabel 3 diketahui bahwa peserta didik dengan skor kemampuan inteligensi, kelas interval 87-89 tidak ada peserta didik. Skor 90 - 92 sebanyak enam peserta didik. Skor 93 - 95 sebanyak sepuluh peserta didik. Skor 96 - 98 sebanyak delapan peserta didik. Skor 99 - 101 enam peserta didik. Skor 102 -104 sebanyak lima peserta didik. Dan skor 105 - 107 sebanyak lima peserta didik.

Setelah data diolah diperoleh nilai rerata (mean) sebesar 97,70, nilai tengah (median) sebesar 97,00, nilai yang sering muncul (modus) sebesar 94, dan standar deviasi sebesar 4,794. Dari data tersebut dapat diklasifikasi distribusi frekuensi kategori kemampuan intelegensi sebagai berikut.

Tabel 4. Distribusi Frekuensi Kategori Kemampuan Intelegensi

\begin{tabular}{|l|c|c|c|c|}
\hline No. & Interval Kelas Nilai & Frekuensi & Persentase & Kategori \\
\hline 1. & $87,00-92,91$ & 6 & I5\% & Rendah \\
\hline 2. & $92,92-102,49$ & 25 & $62,5 \%$ & Sedang \\
\hline 3. & $102,50-107,00$ & 9 & $22,5 \%$ & Tinggi \\
\hline \multicolumn{2}{|l|}{ Total } & 40 & $100 \%$ & \\
\hline
\end{tabular}

Dari tabel 4 dapat diketahui bahwa enam peserta didik atau $15 \%$ memiliki kemampuan inteligensi rendah, dua puluh lima peserta didik atau $62,5 \%$ memiliki kemampuan inteligensi sedang dan sembilang peserta didik atau 22,5\% memiliki kemampuan inteligensi tinggi. Hal ini menunjukkan bahwa kemampuan inteligensi peserta didik SMP Negeri 4 termasuk dalam kategori sedang. 


\section{Task Commitment}

Data task commitment diperoleh dari instrumen berupa angket yang terdiri dari dua jenis pernyataan, yaitu pernyataan positif dan negatif. Penilaian menggunakan skala likert dengan 5 alternatif jawaban (sangat setujuh, setujuh, netral, tidak setujuh, sangat tidak setujuh). Untuk penyekoran pernyataan positif yaitu sangat setujuh adalah 5, setujuh adalah 4 , netral adalah 3 , tidak setujuh adalah 2 , dan sangat tidak setujuh adalah 1. Untuk penyekoran pernyataan negatif yaitu sangat setujuh adalah 1 , setujuh adalah 2 , netral adalah 3 , tidak setujuh adalah 4, dan sangat tidak setujuh adalah 5. Berikut ini adalah penyajian distribusi frekuensi Task Commitment peserta didik.

Tabel 5. Distribusi Frekuensi Task Commitment

\begin{tabular}{|c|c|c|c|c|c|}
\hline \multirow{2}{*}{ No. } & \multirow{2}{*}{$\begin{array}{c}\text { Interval } \\
\text { Kelas }\end{array}$} & \multicolumn{4}{|c|}{ Frekuensi } \\
\hline & & Absolut & Kumulatif & Relatif & Kumulatif \\
\hline 1. & $63-70$ & 6 & 6 & 15 & 15 \\
\hline 2. & $71-78$ & 7 & 13 & 17,5 & 32,5 \\
\hline 3. & $79-86$ & 9 & 22 & 22,5 & 55 \\
\hline 4. & $87-94$ & 8 & 30 & 20 & 75 \\
\hline 5. & $95-102$ & 8 & 38 & 20 & 95 \\
\hline 6. & $103-110$ & 1 & 39 & 2,5 & 97,5 \\
\hline 7. & $111-118$ & 1 & 40 & 2,5 & 100,00 \\
\hline & Total & 40 & & $100 \%$ & \\
\hline
\end{tabular}

Berdasarkan Tabel 5 diketahui bahwa peserta didik dengan skor task commitment, kelas interval $63-70$ sebanyak enam peserta didik. Skor $71-78$ sebanyak tujuh peserta didik. Skor 79 - 86 sebanyak sembilan peserta didik. 
Skor 87 - 94 sebanyak delapan peserta didik. Skor 95 - 102 sebanyak delapan peserta didik. Skor $103-110$ sebanyak satu peserta didik. Dan skor 111 - 118 sebanyak satu peserta didik.

Setelah data diolah diperoleh nilai rerata (mean) sebesar 85,88, nilai tengah (median) sebesar 85,50, nilai yang sering muncul (modus) sebesar 70, dan standar deviasi sebesar 12,262. Dari data tersebut dapat diklasifikasi distribusi frekuensi kategori variabel task commitment sebagai berikut.

Tabel 6. Distribusi Frekuensi Kategori Variabel Task Commitment

\begin{tabular}{|c|c|c|c|c|}
\hline No. & Interval Kelas Nilai & Frekuensi & Persentase & Kategori \\
\hline 1. & $63,00-73,62$ & 6 & $\mathrm{I} 5,0 \%$ & Rendah \\
\hline 2. & $73,63-98,15$ & 27 & $67,5 \%$ & Sedang \\
\hline 3. & $98,16-118,00$ & 7 & $17,5 \%$ & Tinggi \\
\hline
\end{tabular}

Dari tabel 6. dapat diketahui bahwa enam peserta didik atau $15 \%$ memiliki kemampuan task commitment rendah, dua puluh tujuh peserta didik atau $67 \%$ memiliki task commitment sedang dan tujuh peserta didik atau $18 \%$ memiliki task commitment tinggi. Hal ini menunjukkan bahwa kemampuan inteligensi peserta didik SMP Negeri 4 termasuk dalam kategori sedang.

\section{Prestasi Belajar Matematika}

Data prestasi belajar diperoleh dari Instrumen dokumentasi dimana prestasi belajar diperoleh dari nilai rapor matematika yang 
dicapai peserta didik selama dua semester. Data prestasi belajar dapat dilihat pada table 7 .

Tabel 7. Distribusi Frekuensi Prestasi Belajar

\begin{tabular}{|c|c|c|c|c|c|}
\hline \multirow{2}{*}{ No. } & \multirow{2}{*}{$\begin{array}{c}\text { Interval } \\
\text { Kelas }\end{array}$} & \multicolumn{5}{|c|}{ Frekuensi } \\
\cline { 3 - 6 } & Absolut & Kumulatif & Relatif & Kumulatif \\
\hline 1. & $75-77$ & 3 & 3 & 7,5 & 7,5 \\
\hline 2. & $78-80$ & 6 & 9 & 15 & 22,5 \\
\hline 3. & $81-83$ & 12 & 21 & 30 & 52,5 \\
\hline 4. & $84-86$ & 7 & 28 & 17,5 & 70 \\
\hline 5. & $87-89$ & 5 & 33 & 12,5 & 82,5 \\
\hline 6. & $90-92$ & 5 & 38 & 12,5 & 95 \\
\hline 7. & $93-95$ & 2 & 40 & 5 & 100,00 \\
\hline Total & & 40 & & $100 \%$ & \\
\hline
\end{tabular}

Berdasarkan Tabel 7 diketahui bahwa peserta didik dengan skor prestasi belajar, kelas interval 75 - 77 sebanyak tiga peserta didik. Skor 78 - 80 sebanyak enam peserta didik. Skor 81 - 83 sebanyak dua belas peserta didik. Skor $84-86$ sebanyak tujuh peserta didik. Skor 87 - 89 sebanyak lima peserta didik. Skor 90 - 92 sebanyak lima peserta didik. Dan skor 93 - 95 sebanyak dua peserta didik.

Setelah data diolah diperoleh nilai rerata (mean) sebesar 84,08 , nilai tengah (median) sebesar 83,00, nilai yang sering muncul (modus) sebesar 82, dan standar deviasi sebesar 4,859. Dari data tersebut dapat diklasifikasi distribusi frekuensi kategori prestasi belajar sebagai berikut. 
Tabel 8. Distribusi Persentase Frekuensi Kategori Prestasi Belajar

\begin{tabular}{|c|c|c|c|c|}
\hline No. & Interval Kelas Nilai & Frekuensi & Persentase & Kategori \\
\hline 1. & $75,00-79,22$ & 7 & $\mathrm{I} 7,5 \%$ & Rendah \\
\hline 2. & $79,23-89,00$ & 26 & $65 \%$ & Sedang \\
\hline 3. & $90,00-95,00$ & 7 & $17,5 \%$ & Tinggi \\
\hline \multicolumn{2}{|c|}{ Total } & 40 & $100 \%$ & \\
\hline
\end{tabular}

Dari tabel 8 dapat diketahui bahwa tujuh peserta didik atau $17 \%$ memiliki prestasi belajar rendah, dua puluh enam peserta didik atau $65 \%$ memiliki prestasi beljar sedang dan tujuh peserta didik atau $18 \%$ memiliki prestasi belajar tinggi. Hal ini menunjukkan bahwa prestasi belajar peserta didik SMP Negeri 4 termasuk dalam kategori.

\section{Pengujian Prasyarat Analisis}

\section{Uji Normalitas}

Uji normalitas data penelitian ini menggunakan Chi-square. Pada penelitian ini dilakukan tiga kali uji normalitas.

Kemampuan Inteligensi

Tabel 9. Normalitas Data Inteligensi

\begin{tabular}{|l|l|l|l|l|l|l|}
\hline \multirow{2}{*}{} & \multicolumn{4}{|l|}{ Kolmogorov-Smirnova } & \multicolumn{3}{l|}{ Shapiro-Wilk } \\
\cline { 2 - 7 } & Statistic & Df & Sig. & Statistic & df & Sig. \\
\hline Inteligensi & .113 & 40 & $.200^{*}$ & .951 & 40 & .079 \\
\hline
\end{tabular}

Tabel 9 menunjukkan bahwa variabel kemampuan inteligensi adalah berdistribusi normal. Hal itu dilihat dari nilai signifikansi sebesar 0,200. Tampak hasil dari perhitungan Kolmogorov Smirnov Test sudah menunjukkan nilai signifikansi $>0,05$. 


\section{Task Commitment}

Berdasarkan hasil analisis Normalitas Task Commitment diperoleh nilai signifikansi sebesar 0,200. Tampak hasil dari perhitungan Kolmogorov Smirnov Test sudah menunjukkan nilai signifikansi $>0,05$ yang berarti bahwadata tersebut berdistribusi normal.

\section{Prestasi Belajar}

Berdasarkan hasil analisis Normalitas Data Prestasi Belajar diperoleh nilai signifikansi sebesar 0,081. Tampak hasil dari perhitungan Kolmogorov Smirnov Test sudah menunjukkan nilai signifikansi $>0,05$ yang berarti data berdistribusi normal.

\section{Analisis Regresi Linear Berganda}

Digunakan untuk mengetahui pengaruh dari variabel, yaitu Kemampuan Inteligensi $\left(\mathrm{X}_{1}\right)$ dan Task Commitment (X2) terhadap Prestasi Belajar (Y). Analisis data dalam perhitungan regresi linear berganda, maka dapat dilihat hasilnya pada tabel 10 sebagai berikut:

Tabel 10 Hasil Analisis Regresi Linear Berganda

\begin{tabular}{|c|c|c|c|}
\hline \multirow[t]{2}{*}{ Model } & \multicolumn{2}{|c|}{$\begin{array}{l}\text { Unstandardized } \\
\text { Coefficients }\end{array}$} & \multirow{2}{*}{$\begin{array}{c}\begin{array}{c}\text { Standardized } \\
\text { Coefficients }\end{array} \\
\text { Beta }\end{array}$} \\
\hline & B & Std. Error & \\
\hline (Constant) & 99.412 & 18.348 & \\
\hline inteligensi & -.110 & .168 & -.109 \\
\hline $\begin{array}{l}\text { task_com } \\
\text { mitment }\end{array}$ & -.053 & .066 & -.134 \\
\hline
\end{tabular}

persamaan regresi linear berganda sebagai berikut :

$\mathrm{Y}=99,412+(-0,110) \mathrm{X}_{1}+(-0,053) \mathrm{X}_{2}$ 


\section{Uji Hipotesis}

Berdasarkan hasil analisis uji-F diperoleh nilai $\mathrm{F}$ hitung 0,460 pada tingkat signifikan $5 \%(0,05)$ nilai $p=0,635$, karena $p>0,05$ yang berarti bahwa variabel kemampuan inteligensi $\left(\mathrm{X}_{1}\right)$ dan task commitment $\left(\mathrm{X}_{2}\right)$ secara bersama- sama berpengaruh nyata terhadap prestasi belajar matematika peserta didik kelas VIII SMPN 4 Sendana.

\section{SIMPULAN}

Dari hasil analisis data diperoleh bahwa kemampuan inteligensi dan task commitment secara bersama-sama berpengaruh terhadap prestasi belajar matematika peserta didik kelas VIII SMPN 4 Sendana.

\section{SARAN DAN REKOMENDASI}

Diharapakan agar setiap sekolah mengadakan tes intelegensi pada saat penerimaaan siswa karena berpengaruh terhadap prestasi belajar, selain itu guru juga diharapkan mengoreksi dan mengembalikan setiap pekerjaan atau hasil ulangan matematika dengan disertai komentar spesifik mengenai hasil pekerjaan peserta didik agar peserta didik mengetahui kebenaran dan kesalahannya.

\section{DAFTAR PUSTAKA}

Djamarah Syaiful Bahri. 2002. Strategi Belajar Mengajar. Jakarta : PT RINEKA CIPTA

Dajan Anto. 1986. Pengantar Metode Statistika Jilid II. Jakarta : PT

Pustaka LP3ES Indonesia Anggota IKAPI

Lestari Eka Karunia. 2015. Penelitian Pendidikan Matematika. Bandung : PT Refika Aditama

Sardiman. 2014. Interaksi dan Motivasi Belajar dan Mengajar. Jakarta : PT Rajagrafindo Persada

Soemanto Wasty. 1998. Psikologi Pendidikan. Jakarta : PT RINEKA CIPTA 
Siregar Sofian. 2014. Statistika Deskriptif untuk Penelitian: Dilengkapi Perhitungan Manual dan Aplikasi SPSS Versi 17. Jakarta :

Rajawali Pers

Sugiyono. 2011. Metode Penelitian Kuantitatif Kualitatif dan R\&D. Bandung : Alfabeta

Sugiyono. 2012. Statistika untuk Peneliti. Bandung : Alfabeta Syarifa Alvie. 2011. Hubungan antara Dukungan Sosial Orang Tua dengan Komitmen terhadap Tugas (Task commitment) pada Peserta didik Akselerasi tingkat SMA (http://strorage/emulated/o/UCDownloads/artiel/html. diakses 24 juli 2016)

Tiro Muhammad Arif. 2007. Statistika Terapan. Makassar : Andira publisher

Wiranataputra. S. Udin.dkk. 2007. Teori Belajar dan Pembelajaran. Jakarta : Universitas Terbuka 